\title{
Errata
}

To the paper

\section{COLD NEUTRON PROMPT GAMMA ACTIVATION ANALYSIS AT NIST: A PROGRESS REPORT}

\author{
R. L. PAUL,** R. M. LINDSTROM,* D. H. VINCENT**
}

*Inorganic and Analytical Research Division, National Institute of Standards and Technology, Gaithersburg, MD 20899 (USA)

**Department of Nuclear Engineering. The University of Michigan, Ann Arbor, Michigan 48109 (USA)

appeared in the

Journal of Radioanalytical and Nuclear Chemistry, Articles, Vol. 180, No. 2 (1994) 263-269.

On page number 267 the second paragraph is as follows:

Elemental concentrations were calculated as either $\%$ by weight of sample or as parts per million (ppm) of sample weight. These values are listed in Table 2, along with values from the literature. Our analyses are in fair agreement with values given by JAROSEWICH. ${ }^{8}$ Hydrogen concentrations from SCOON ${ }^{10}$ and WILLIS ${ }^{11}$ were determined as $\mathrm{H}_{2} \mathrm{O}$ using the Penfield water determination method. These results are in fair agreement with our total hydrogen concentration.

Table 2

Elemental concentrations in Allende

\begin{tabular}{lcc}
\hline & \multicolumn{2}{c}{ Concentration } \\
\cline { 2 - 3 } Element & This work & Literature \\
\hline Si (\%) & $15.6 \pm 0.1$ & $16.02 \pm 0.10^{8}$ \\
Fe (\%) & $21.4 \pm 0.1$ & $23.57 \pm 0.08^{8}$ \\
Mg (\%) & $13.7 \pm 0.2$ & $14.83 \pm 0.12^{8}$ \\
Al (\%) & $1.71 \pm 0.02$ & $1.74 \pm 0.04^{8}$ \\
Ca (\%) & $1.64 \pm 0.04$ & $1.84 \pm 0.07^{8}$ \\
Ni (\%) & $1.60 \pm 0.02$ & $1.42 \pm 0.02^{8}$ \\
S (\%) & $2.11 \pm 0.02$ & $2.10 \pm 0.03^{8}$ \\
Cr (\%) & $0.43 \pm 0.09$ & $0.36 \pm 0.01^{8}$ \\
Mn (\%) & $0.19 \pm 0.01$ & $0.15 \pm 0.01^{8}$ \\
Na (\%) & $0.31 \pm 0.01$ & $0.34 \pm 0.01^{8}$ \\
Ti (ppm) & $840 \pm 30$ & $900 \pm 60^{8}$ \\
Cl (ppm) & $293 \pm 10$ & $316,265^{9}$ \\
H (ppm) & $160 \pm 10$ & $190,180^{10}$ \\
K (ppm) & $380 \pm 70$ & $110,150^{11}$ \\
\hline
\end{tabular}

Elsevier Science S. A., Lausanne Akadémiai Kiadó, Budapest 


\title{
References
}

8. E. JAROSEWICH, R. S. CLARKE, Jr., J. N. BARROWS, Neutron Activation Analyses of Seven Elements in the Allende Meteorite Reference Sample, in: The Allende Meteorite Reference Sample, E. JAROSEWICH, R. S. CI ARKE Jr., J. N. Barrows (Eds), Smithsonian Contrib, Earth Sci., 27 (1987) 1.

9. K. S. HEIR, A. O. BRUMFELT, E. STEINNES, B. SUNDVOLL, Neutron Activation Analyses of Seven Elements in the Allende Meteorite Reference Sample, in: The Allende Meteorite Reference Sample, E. JAROSEWICH, R. S. CLARKE, Jr., J. N. Barrows (Eds), Smithsonian Contrib., Earth Sci., 27 (1987) 24.

10. J. H. SCOON, Bulk Chemical Analysis of the Allende Meteorite Reference Sample, in: The Allende Meteorite Reference Sample, E. JAROSEWICH, R. S. CLARKE, Jr., J. N. Barrows (Eds), Smithsonian Contrib, Earth Sci., 27 (1987) 39.

11. J. P. WILLIS, X-ray Fluorescence Spectrometric Analysis of the Allende Meteorite Reference Sample, in: The Allende Meteorite Reference Sample. E. JAROSEWICH, R. S. CLARKE, Jr., J. N. Barrows (Eds), Smithsonian Contrib., Earth Sci., 27 (1987) 46.

$*$

To the paper

\section{RADIOMETRIC MICROBIOLOGICAL ESTIMATION OF VITAMIN $B_{12}$}

\author{
S. JAVAID KHURSHID \\ Nuclear Chemistry Division. Pakistan Institute of Nuclar Science and Technology, \\ P.O. Nilore, Islamabad (Pakistan)
}

appeared in the

Journal of Radioanalytical and Nuclear Chemistry, Articles, Vol, 185, No. 1 (1994) 167-171.

On page number 168, line 17: $\mathrm{CO}_{2}$ should be written instead of $\mathrm{CO}$.

On page number 170, line 10: words "and radioisotopic" have been repeated which should be deleted.

On page number 170 , line 22 : words "and rapid" should be deleted. 